(n)

\title{
Post-first-line FOLFOX chemotherapy for grade 3 neuroendocrine carcinoma
}

\author{
J Hadoux ${ }^{1}$, D Malka ${ }^{2}$, D Planchard ${ }^{3}$, J Y Scoazec ${ }^{4}$, C Caramella ${ }^{5}$, J Guigay ${ }^{6}$, V Boige ${ }^{2}$, \\ S Leboulleux', P Burtin ${ }^{2}$, A Berdelou', Y Loriot ${ }^{7}$, P Duvillard ${ }^{4}$, C N Chougnet $^{8}$, \\ D Déandréis', M Schlumberger', I Borget ${ }^{9,10}$, M Ducreux ${ }^{2,10}$ and $E$ Baudin'
}

Departments of ${ }^{1}$ Nuclear Medicine and Endocrine Tumors, ${ }^{2}$ Digestive Oncology, ${ }^{3}$ Medical Oncology (Thoracic Group), ${ }^{4}$ Pathology, and ${ }^{5}$ Radiology, Gustave Roussy, 114 Rue Edouard Vaillant, F-94800 Villejuif Cedex, France ${ }^{6}$ Centre Antoine Lacassagne, CLCC, 33, Avenue de Valombrose, F-06189 Nice, France

${ }^{7}$ Department of Urologic Oncology, Gustave Roussy, 114 Rue Edouard Vaillant, F-94800 Villejuif Cedex, France ${ }^{8}$ Department of Endocrinology, Hôpital Saint Louis - APHP, 1, Avenue Claude-Vellefaux, F-75010 Paris, France ${ }^{9}$ Department of Biostatistics and Epidemiology, Gustave Roussy, 114 Rue Edouard Vaillant, F-94800 Villejuif Cedex, France

${ }^{10}$ Faculté de Médecine, Paris-Sud University, F-94270 Le Kremlin Bicêtre, France

Correspondence should be addressed to E Baudin Email eric.baudin@gustaveroussy.fr

\begin{abstract}
There is no standard for second-line chemotherapy in poorly differentiated grade 3 neuroendocrine carcinoma (G3-NEC) patients. We analyzed the antitumor efficacy of 5 -fluorouracil and oxaliplatin (FOLFOX) chemotherapy in this population. A single-center retrospective analysis of consecutive G3-NEC patients treated with FOLFOX chemotherapy after failure of a cisplatinum-based regimen between December 2003 and June 2012 was performed. Progression-free survival (PFS), overall survival (OS), response rate, and safety were assessed according to RECIST 1.1 and NCI.CTC v4 criteria. Twenty consecutive patients were included (seven males and 13 females; median age 55; range 23-87 years) with a performance status of $0-1$ in $75 \%$ of them. Primary location was gastroenteropancreatic in 12 , thoracic in four, other in two, and unknown in two patients. There were $12(65 \%)$ large-cell and 7 (30\%) small-cell G3-NEC tumors, and $1(5 \%)$ unknown. All patients had distant metastases. Twelve (60\%) patients received FOLFOX as second-line treatment and $8(40 \%)$ as third-line treatment or later and the median number of administered cycles was 6 (range 3-14). The median follow-up was 19 months. Median PFS was 4.5 months. Among the 17 evaluable patients, five partial responses (29\%), six stable diseases (35\%), and six progressive diseases (35\%) were observed. Median OS was 9.9 months. Main Grade 3-4 toxicities were neutropenia (35\%), thrombopenia (20\%), nausea/vomiting (10\%), anemia $(10 \%)$, and elevated liver transaminases $(10 \%)$. Our results indicate that the FOLFOX regimen could be considered as a second-line option in poorly differentiated G3-NEC patients after cisplatinum-based first-line treatment but warrant further confirmation in future larger prospective studies.
\end{abstract}

\author{
Key Words \\ - neuroendocrine carcinoma \\ - grade 3 \\ - poorly differentiated \\ neuroendocrine tumor \\ - oxaliplatin \\ - FOLFOX \\ - second-line chemotherapy
}

Endocrine-Related Cancer (2015) 22, 289-298
(C) 2015 Society for Endocrinology Printed in Great Britain
Published by Bioscientifica Ltd 


\section{Introduction}

Neuroendocrine tumors (NETs) constitute a heterogeneous group of diseases that share a common definition (i.e., the expression of specific markers of peptideproducing neuroendocrine cells). NETs are rare (Yao et al. 2008) and exhibit a very heterogeneous prognosis. Pathological differentiation or grading and TNM stage are the most important prognostic factors (Baudin 2007). Poorly differentiated neuroendocrine carcinomas (NECs) are characterized by a poorer outcome when compared with well-differentiated NET independently of the TNM stage or the primary location (Madeira et al. 1998, Travis et al. 1998, Rindi et al. 1999, Lim et al. 2005, Asamura et al. 2006, Faggiano et al. 2007, Scarpa et al. 2010, Panzuto et al. 2011, Strosberg et al. 2011). These tumors, when located in the digestive system, are classified as WHO grade 3 NEC (G3-NEC), characterized by a poorly differentiated morphology, a mitotic count above 20/10 high-power field (10 HPF), and/or a Ki67 expression level exceeding $20 \%$ (Rindi 2010). Our group has recently reported that the grade 3 NET (G3-NET) category should also be considered, as some tumors, with a mitotic count above 20/10 HPF and/or a Ki67 expression level of over $20 \%$, present a welldifferentiated morphology and more importantly different prognosis and behavior (Vélayoudom-Céphise et al. 2013). When located in the lungs, these NECs are defined by a poorly differentiated morphology, a mitotic index above ten mitoses per $10 \mathrm{HPF}$, and are subcategorized into largecell and small-cell NECs (Travis et al. 2004). Based on the results obtained mainly for small-cell lung cancer (SCLC), and also a few historical retrospective studies that focused on non-small-cell lung NEC, a cisplatin/etoposide combination (Moertel et al. 1991, Garrow et al. 1993, Mitry et al. 1999) is recommended as first-line chemotherapy for G3NEC patients (Pavel et al. 2012). This regimen produced a $31 \%$ response rate (RR) and a median overall survival (OS) of 11 months for 252 patients receiving this regimen as first-line treatment in the largest retrospective study to date (Sorbye et al. 2012). Notably, patients with Ki67 <55\% had a lower RR but an improved OS, indicating prognostic heterogeneity (Sorbye et al. 2012). Indeed, in addition to the proliferative index, primary location, chromogranin A $(\mathrm{CgA})$ staining, and cell subtypes have been proposed as additional prognostic parameters of NEC (Travis et al. 1991, Faggiano et al. 2007, Sorbye et al. 2012).

Effective second-line chemotherapies for G3-NEC are urgently needed. Indeed, recurrence invariably occurs in these patients under or after completion of cisplatinumbased chemotherapy. Recently, the results of second-line (folinic acid, 5-fluorouracil and irinotecan (FOLFIRI)) regimen in G3-NEC have been reported for 19 patients with an RR of $31 \%$ and a median progression-free survival (PFS) of 4 months (Hentic et al. 2012). A few years ago, capecitabine and oxaliplatin (XELOX) chemotherapy was used in the first-line treatment of 13 patients with poorly differentiated NETs: the RR was 23\% and the median time to progression was 4 months (range 1-43) (Bajetta et al. 2007). More recently, temozolomide chemotherapy combined with capecitabine and/or bevacizumab was also proposed as an alternative for patients with neuroendocrine neoplasms and high proliferative index (Welin et al. 2011). However, the applicability of this regimen in patients with G3-NEC in comparison with the recently identified G3-NET remains undetermined in the absence of analysis of the morphological differentiation pattern (Vélayoudom-Céphise et al. 2013, Sorbye et al. 2014). To further address the role of oxaliplatin-based chemotherapy in G3-NEC patients, we retrospectively reviewed the efficacy and safety of FOLFOX, after failure of a cisplatin-etoposide regimen.

\section{Materials and methods}

\section{Patients}

Consecutive patients treated between December 2003 and June 2012 for a G3-NEC with FOLFOX chemotherapy at Gustave Roussy (Villejuif, France) were included. Inclusion criteria were: i) a confirmed pathology diagnosis of poorly differentiated G3-NEC based on both morphology and grade by expert pathologists (P Duvillard and J Y Scoazec) with absence of mixed or welldifferentiated architectures; ii) performance status of 0-2 and normal cardiac, renal, liver, and blood cell functions and blood count; iii) recovery from toxic effects of previous chemotherapy as defined by grade $0-1$ persistent toxicity; iv) at least one cycle of FOLFOX chemotherapy; and v) documented disease progression before the beginning of FOLFOX. Small-cell lung carcinoma was excluded, but cases of large-cell NEC of the lung as defined by the current WHO Classification (2004) were included. In addition, available histological material was carefully reviewed in order to exclude any welldifferentiated tumors with elevated Ki67, i.e., grade 3 well-differentiated NETs as described recently (Vélayoudom-Céphise et al. 2013). No minimum cut-off was used to define CgA positivity.

Published by Bioscientifica Ltd 
The following parameters were collected: age, sex, performance status, presence of a functioning syndrome, primary location, TNM stage according to UICC 2010, pathological parameters including Ki67 and/or mitotic index (Ki67 was classified according to the Ki67 cut-off of $55 \%$ as recently highlighted in the NORDIC study; Sorbye et al. 2012), cell size (i.e., large or small cell), CgA, neuron-specific enolase (NSE), and synaptophysin staining on tumorous samples; NSE, CgA, and lactate dehydrogenase (LDH) levels in the blood were classified as elevated if above 2, the upper normal range. Regarding therapy, the following parameters were collected: duration of treatment and response to first-line cisplatin-etoposide combination, date of FOLFOX initiation, schedules of chemotherapy, number of cycles administered, toxicity according to the National Cancer Institute Common Terminology Criteria (NCI-CTC) v.4.0, dose adjustment, response and duration of response according to RECIST 1.1, and reason for FOLFOX discontinuation. The status of all patients (in terms of survival and progression status) was recorded on 22nd March 2014; causes of death were also recorded.

\section{Chemotherapy}

The FOLFOX4 regimen consisted of a $2 \mathrm{~h}$-infusion of oxaliplatin $85 \mathrm{mg} / \mathrm{m}^{2}$, a $2 \mathrm{~h}$-infusion of leucovorin $400 \mathrm{mg} / \mathrm{m}^{2}, 5$-fluorouracil (5-FU) $400 \mathrm{mg} / \mathrm{m}^{2}$ as a $10 \mathrm{~min}$ bolus injection, and 5 -FU $2400 \mathrm{mg} / \mathrm{m}^{2}$ as a $46 \mathrm{~h}$-infusion; cycles were repeated every 2 weeks.

Dose reductions were made as follows. Suppression of 5-FU bolus was performed at the first occurrence of grade 3 or 4 neutropenia or thrombocytopenia (or both), diarrhea, stomatitis, or other drug-related adverse effects of grade 3. In cases of recurrence (especially of mucosal, digestive, or skin toxicities) or neurological toxicity, infusional 5-FU, and oxaliplatin (especially for grade 3-4 neutropenia or thrombopenia) doses were also reduced from 25 to $50 \%$. Oxaliplatin was reduced in cases of persistent grade 2 neurological toxicity. Chemotherapy was stopped in the event of cardiac or grade 3 or 4 allergic reactions.

\section{Safety and efficacy}

Toxicities were graded according to the NCI.CTC v.4.0. Clinical examination and routine laboratory tests were performed before every chemotherapy cycle. Tumor stage and monitoring were assessed by thorax and abdomen computed tomography (CT) scans and fluorine-18-deoxyglucose positron emission tomography (FDG-PET), when feasible in the setting of emergency, at baseline and then every 8 weeks during chemotherapy. At the end of the treatment, CT-scans were performed every 2 months.

All patients who received at least one cycle of study treatment were considered as assessable for survival, PFS analysis, and toxicity. Response was assessed by local radiologists according to RECIST 1.1 (Eisenhauer et al. 2009).

\section{Statistical analysis}

This was a monocentric retrospective study of patients treated at Gustave Roussy. The PFS was defined as the time from the date of the first chemotherapy course to the date of the first event (cancer progression or, death from any cause) or to the last follow-up. The OS was defined as the duration between the date of the first chemotherapy course to the date of death from any cause or of the last follow-up.

The median follow-up was estimated by the reverse Kaplan-Meier method (Schemper's method). Survival curves were calculated by the Kaplan-Meier method and generated using the TIGRE Software developed at Gustave Roussy. Survival data were expressed as durations in months with range and median survival calculated. The comparisons of survival curves between patient groups were performed by a log-rank test.

Quantitative data were expressed as absolute numbers and medians. Qualitative data were expressed as percentages of the whole population. Correlation between response to first-line chemotherapy and response to FOLFOX was performed by Fisher's exact test.

\section{Results}

\section{Patient characteristics}

Twenty-one patients received oxaliplatin-based chemotherapy for G3-NEC at our institution between December 2003 and June 2012. One patient was excluded from the analysis because he received FOLFOX $4+$ bevacizumab as first-line treatment. Finally, 20 patients were included in this study, as described in Table 1, consisting of seven males and 13 females, with a median age of 55 years (range 23-87) and a performance status of $0-1$ in 15 (75\%) patients. The oldest patient was an 87-year-old woman who suffered an esophagus G3-NEC. A large-cell feature was found in 12 patients (60\%). Tumor Ki67 exceeded $55 \%$ in 12 out of 18 evaluable patients (Table 1). Primary locations were digestive (three pancreas, two esophagus, two cecum, two rectum, two stomach, and one ileo-cecal), thoracic (two thymus and two bronchus), bladder (1), and

Published by Bioscientifica Ltd. 
Table 1 Characteristics of patients

\begin{tabular}{|c|c|}
\hline Characteristics & $n=20(100 \%)$ \\
\hline Median age & 55 (range 23-87) \\
\hline Male & $7(35 \%)$ \\
\hline \multicolumn{2}{|l|}{ Performance status } \\
\hline 0 & $5(25 \%)$ \\
\hline 1 & $9(45 \%)$ \\
\hline 2 & $3(15 \%)$ \\
\hline$>2$ & $2(10 \%)$ \\
\hline Missing & $1(5 \%)$ \\
\hline \multicolumn{2}{|l|}{ Cell subcategories } \\
\hline Large cell & $12(60 \%)$ \\
\hline Small cell & $7(35 \%)$ \\
\hline Unknown & $1(5 \%)$ \\
\hline \multicolumn{2}{|l|}{ Primary } \\
\hline Gastroenteropancreatic & $12(60 \%)$ \\
\hline Lung and thymus & $4(20 \%)$ \\
\hline Unknown & $3(15 \%)$ \\
\hline Bladder & $1(5 \%)$ \\
\hline Functioning tumor & $1(5 \%)$ \\
\hline \multicolumn{2}{|l|}{ Ki67 (\%) } \\
\hline$<55$ & $6(30 \%)$ \\
\hline$>55$ & $12(60 \%)$ \\
\hline Unknown & $2(10 \%)$ \\
\hline \multicolumn{2}{|l|}{ Stage } \\
\hline Metastatic disease & $20(100 \%)$ \\
\hline $\begin{array}{l}\text { Median number of metastatic } \\
\text { sites }\end{array}$ & 2 (range $1-5)$ \\
\hline \multicolumn{2}{|l|}{ Metastatic sites } \\
\hline Lung & $6(30 \%)$ \\
\hline Lymph nodes & $11(55 \%)$ \\
\hline Liver & $11(55 \%)$ \\
\hline Bone & $4(20 \%)$ \\
\hline Others & $13(65 \%)$ \\
\hline \multicolumn{2}{|l|}{ First-line chemotherapy } \\
\hline Cisplatin/etoposide & $13(65 \%)$ \\
\hline Carboplatin/etoposide & $5(25 \%)$ \\
\hline PAVEP & $1(5 \%)$ \\
\hline TIP & $1(5 \%)$ \\
\hline \multicolumn{2}{|l|}{ Line of treatment } \\
\hline 2nd line & $12(60 \%)$ \\
\hline 3rd-4th lines & $6(30 \%)$ \\
\hline$>4$ th line & $2(10 \%)$ \\
\hline \multicolumn{2}{|l|}{ Post-first-line chemotherapies } \\
\hline \multicolumn{2}{|l|}{ Systemic treatment } \\
\hline FOLFIRI & $3(15 \%)$ \\
\hline Taxol/gemcitabine & $1(5 \%)$ \\
\hline Temozolomide & $1(5 \%)$ \\
\hline Topotecan & $1(5 \%)$ \\
\hline Sunitinib & $2(10 \%)$ \\
\hline Temsirolimus & $1(5 \%)$ \\
\hline \multicolumn{2}{|l|}{ Loco-regional treatment } \\
\hline Radiation therapy & $3(15 \%)$ \\
\hline Surgery & $2(10 \%)$ \\
\hline
\end{tabular}

PAVEP, cyclophosphamide, doxorubicin, etoposide, and cisplatin; TIP, paclitaxel, ifosfamide, and cisplatin; FOLFIRI, folinic acid, 5-fluorouracil and irinotecan.

unknown (3). Tumors were mainly nonfunctioning except for one patient who suffered a paraneoplastic Cushing's syndrome. FDG uptake in tumors was positive in 14 of the 15 patients in whom it was examined. All patients had stage IV (M1) disease, as defined by metastases in distant organs in all patients except for two who presented with distant lymph node metastases. A high level of NSE in the blood was found in $41.2 \%$ of cases (seven out of 17 patients) and a high level of $\mathrm{LDH}$ in $31 \%$ of them (four out of 13 patients). CgA immunohistochemistry staining was found to be positive in the tumor samples of 80\% (16 patients) as defined by J Y Scoazec, and CgA was elevated in plasma at baseline in $69 \%$ of cases (11 out of 16 patients). Median Ki67 was 70\% (range 30-95).

All patients had received a platinum-based regimen before beginning FOLFOX as detailed in Table 1 and some patients also received other post-first-line chemotherapies before FOLFOX. During first-line cisplatin-based regimen, five partial responses (PR, 25\%), four stable diseases (SD, $20 \%$ ), and 11 progressive diseases (PD, 55\%) were reported. Median time from the end of first-line platinum-based therapy to FOLFOX was 1.4 months (range 1-30.3).

\section{Efficacy and survival}

Three patients were given reduced doses of chemotherapy due to persistent grade 1 neurologic or hematologic toxicities: one patient received modified FOLFOX4 with $80 \%$ of the dose of the infusional $5-\mathrm{FU}$, one patient received modified FOLFOX 4 with a 50\% dose reduction in oxaliplatin, and one patient received single agent oxaliplatin $130 \mathrm{mg} / \mathrm{m}^{2}$ every 3 weeks. Finally, after cisplatinbased chemotherapy, 17 out of 20 patients were eligible for the full-dose FOLFOX4 regimen.

FOLFOX was administered as a second-line chemotherapy in 12 patients (60\%) and as third- or later-line chemotherapy in eight patients (40\%). Seventeen patients were evaluable for tumor response according to RECIST 1.1 criteria. Three patients were deemed to be not evaluable: one had myocardium-only metastasis and was considered to have SD on myocardium magnetic resonance imaging (MRI), one had bone-only metastasis and was considered to have SD on MRI (no FDG-PET evaluation was performed for this patient), and one patient died of septic shock before the first evaluation. Out of the 17 evaluable patients, no complete response, five PR (29\%), six SD (35\%), and six PD (35\%) were observed (Table 2).

After a median follow-up of 19.2 months, median PFS was 4.5 months and median OS was 9.9 months (Fig. 1). Five patients $(25 \%)$ remained progression free for more than 6 months. These patients had thymus (2), unknown (1), pancreas (1), and bronchus (1) primary; three had progressed under first-line platinum-based therapy and

Published by Bioscientifica Ltd. 
Table 2 Responses and duration of responses to first-line etoposide-platinum therapy and to FOLFOX

\begin{tabular}{|c|c|c|c|}
\hline & \multicolumn{3}{|c|}{ Response to FOLFOX $(n)$} \\
\hline & PR & SD & PD \\
\hline \multicolumn{4}{|c|}{$\begin{array}{l}\text { Response to first-line } \\
\text { platinum }(n)\end{array}$} \\
\hline PR & 0 & $2(3.6-4.6)$ & $2(1.9-4.1)$ \\
\hline SD & $2(2.3-11)$ & $1(4.7)$ & $1(2.1)$ \\
\hline PD & $3(4.5-6.2)$ & $3(1.3-7.3)$ & $3(2.4-3.6)$ \\
\hline
\end{tabular}

Duration of response range is given from day 1 of FOLFOX therapy in brackets.

two had SD; finally, three of them received FOLFOX as a second line of treatment. There was no difference in terms of RRs according to the 55\% Ki67-cutoff (Fisher's exact test, $P=0.33)$. Differences in terms of PFS and OS according to subgroups are summarized in Table 3. In terms of PFS, the univariate analysis revealed that median PFS was longer for patients with Ki67 $<55 \%$ versus $>55 \%$ (6.2 months versus 3.6 months respectively) $(P=0.0157)$ (Fig. 2), similarly for median OS (19.5 months versus 8.5 months) $(P=0.0087)$. PFS was longer for patients whose tumors had a positive $\mathrm{CgA}$ staining than for those whose tumors were negative (4.6 months versus 2.1 months, $P=0.0018$ ). OS was also different between these two groups (11.7 months versus 4.6 months respectively, $P=0.0124)$. No differences in terms of PFS and OS were observed according to the pathology and the primary site, or in case of dose reduction (Table 3).

We found no clear correlation between the response to first-line platinum-based regimen (PR or SD) and the response to FOLFOX treatment (paired Fisher's exact test, $P=0.63$ ). Among nine patients who had PD under firstline platinum therapy, there were three PR, three SD, and three PD to FOLFOX (Table 2).

\section{Safety}

Patients received a median number of six cycles of FOLFOX (range 3-14). One patient died of septic shock due to eso-bronchial fistula related to his esophageal primary tumor before the first evaluation, and there was no neutropenia during this event.

Dose adjustments were necessary for 12 out of 20 patients (60\%) including eight oxaliplatin dose adjustments. Neurotoxicity occurred in 16 patients (80\%), mostly grade 1 (11 patients), but one patient experienced G3 neurotoxicity. Most frequent adverse events were asthenia in 16 patients (80\%; G3 in 10\% of cases), nausea and/or vomiting in eight patients (40\%; G3 in 10\%), and diarrhea in seven patients (35\%, G3 in 5\%). Grades 3-4 anemia, thrombopenia, and neutropenia occurred in 2 (10\%), 4 (20\%), and 7 (35\%) patients respectively. No neutropenic fever was diagnosed. No discontinuation for safety reasons was reported. Safety data are summarized in Table 4.

\section{Discussion}

Poorly differentiated NET or G3-NEC according to the digestive WHO 2010 Classification (Rindi 2010) is a rare and aggressive disease for which urgent therapeutic intervention is required as soon as the diagnosis is confirmed by expert pathologists. G3-NEC patients enrolled in this study were reviewed to ensure that the
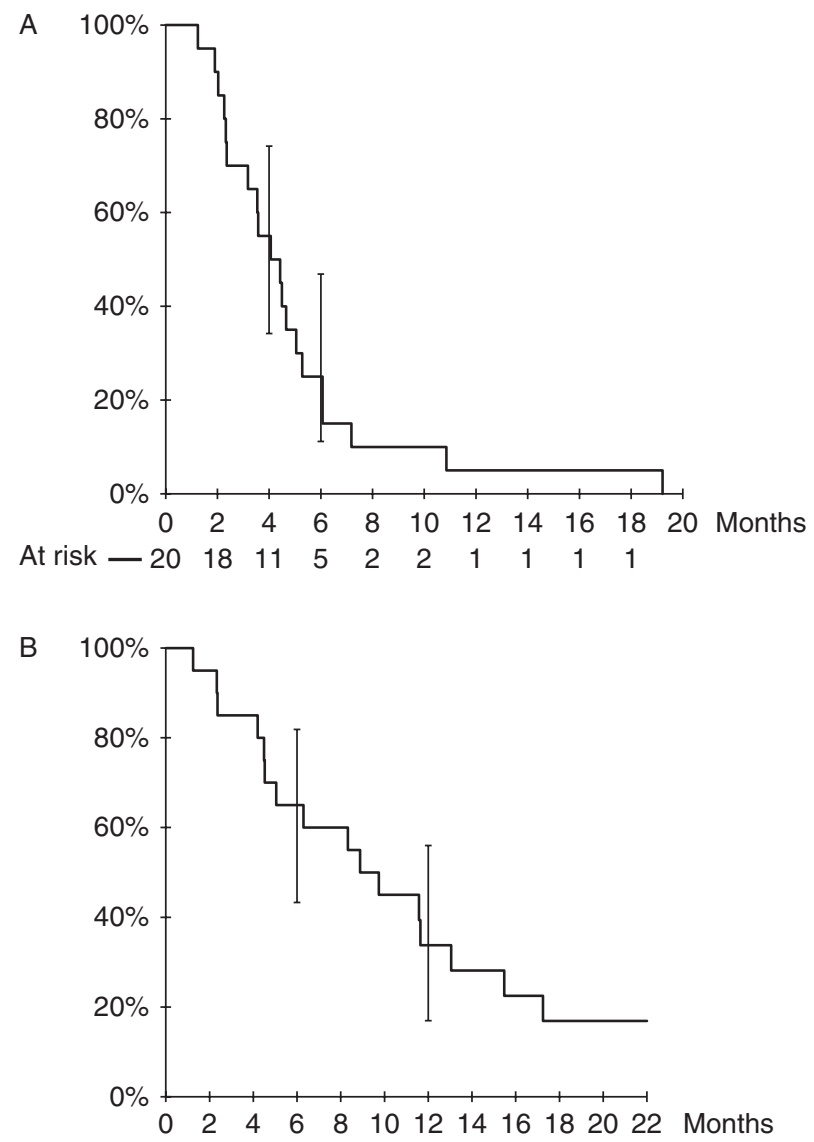

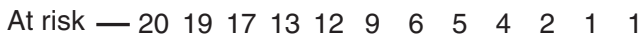

\section{Figure 1}

Survival for entire patient cohort. (A) Progression-free survival curve. Four-month PFS was $50 \%, 95 \% \mathrm{Cl}(30-70 \%)$ and six-month PFS was $20 \%$, $95 \% \mathrm{Cl}(8-41 \%)$. (B) Overall survival curve. Six-month OS was $65 \%$; $95 \% \mathrm{Cl}(43-81 \%)$ and 12 -month OS was $34 \% ; 95 \% \mathrm{Cl}(17-56 \%)$.

Published by Bioscientifica Ltd. 
Table 3 Univariate survival analysis

\begin{tabular}{|c|c|c|c|c|}
\hline Patient groups & $\begin{array}{c}\text { Median PFS } \\
\text { (months) }\end{array}$ & $\boldsymbol{P}$ & $\begin{array}{c}\text { Median os } \\
\text { (months) }\end{array}$ & $\boldsymbol{P}$ \\
\hline Overall & 4.1 & NA & 9 & NA \\
\hline \multicolumn{5}{|l|}{ Ki67 (\%) } \\
\hline$<55$ & 6.2 & \multirow[t]{2}{*}{0.0157} & 19.5 & \multirow[t]{2}{*}{0.0087} \\
\hline$>55$ & 3.6 & & 8.5 & \\
\hline \multicolumn{5}{|l|}{$\mathrm{CgA}$ staining } \\
\hline Positive & 4.6 & \multirow[t]{2}{*}{0.0018} & 11.7 & \multirow[t]{2}{*}{0.0124} \\
\hline Negative & 2.1 & & 4.6 & \\
\hline \multicolumn{5}{|l|}{ Histology } \\
\hline Small cell & 4.5 & \multirow[t]{2}{*}{0.564} & 8.5 & \multirow[t]{2}{*}{0.384} \\
\hline Large cell & 5.1 & & 11.8 & \\
\hline \multicolumn{5}{|l|}{ Primary } \\
\hline GEP & 4.5 & \multirow[t]{2}{*}{0.1227} & 9 & \multirow[t]{2}{*}{0.1686} \\
\hline Non-GEP & 6.1 & & 15.7 & \\
\hline \multicolumn{5}{|l|}{ Dose reduction } \\
\hline No & 4.6 & \multirow[t]{2}{*}{0.77} & 9.9 & \multirow[t]{2}{*}{0.54} \\
\hline Yes & 4.5 & & 10.8 & \\
\hline
\end{tabular}

NA, not applicable

WHO 2010 definition was met including both the poorly differentiated status and high proliferative index. According to recent recommendations (Pavel et al. 2012), first-line chemotherapy relies on a cisplatin-etoposide combination, which is mostly extrapolated from the results of this regimen in SCLC including meta-analysis (Mascaux et al. 2000, Pujol et al. 2000). Recently, FOLFOX or FOLFIRI regimens have been proposed as potential firstline alternatives (Bajetta et al. 2007, Okita et al. 2011, Du et al. 2013). Results for second-line treatment are even rarer. Recently, Hentic et al. (2012) have more specifically addressed the question of second-line chemotherapy in poorly differentiated NEC and reported the efficacy of a second-line chemotherapy regimen (FOLFIRI) in this setting. The RR was $31 \%$, disease stabilization occurred in $31 \%$ of patients, and the median PFS was 4 months in digestive NEC among which well-differentiated NET with Ki67 exceeding 20\% were excluded from the analysis, as in our study. Different chemotherapy regimens have been investigated in the second-line setting, which are summarized in Table 5. Our results with the FOLFOX regimen are in the range of those reported by Hentic and colleagues with a $29 \%$ RR, $35 \%$ of disease stabilization, and a median PFS of 4.3 months. Altogether, these data support the use of either the FOLFOX or FOLFIRI regimen as second-line options in this setting. Notably, the recently published lack of response with topotecan alone, which belongs to the same family of topoisomerase type 1 inhibitor like irinotecan, indicates that the combination of drugs may be of added value (Olsen et al. 2014). In the second-line setting, Welin et al. (2011) also proposed temozolomide plus or minus 5-FU and bevacizumab as an option in patients with Ki67 above 20\%, but no review of the pathological differentiation of the tumors was performed and results from one recent study did not confirm antitumor activity of temozolomide in NEC (Olsen et al. 2012). We suggest that patients with well-differentiated G3-NET could have been enrolled in Welin's study (Vélayoudom-Céphise et al. 2013). Therefore, the relevance of temozolomide use for G3-NEC remains yet to be established. We strongly suggest that expert pathological review should constitute a critical prerequisite for the analysis of future trials in this field. Finally, retreatment with cisplatin or carboplatin- and etoposidebased chemotherapy is also considered a valuable option after treatment break in case of initial response (Sørensen et al. 2010, Sorbye et al. 2012).

Our results indicate a different behavior of G3-NEC with regard to prognosis and response to chemotherapy as

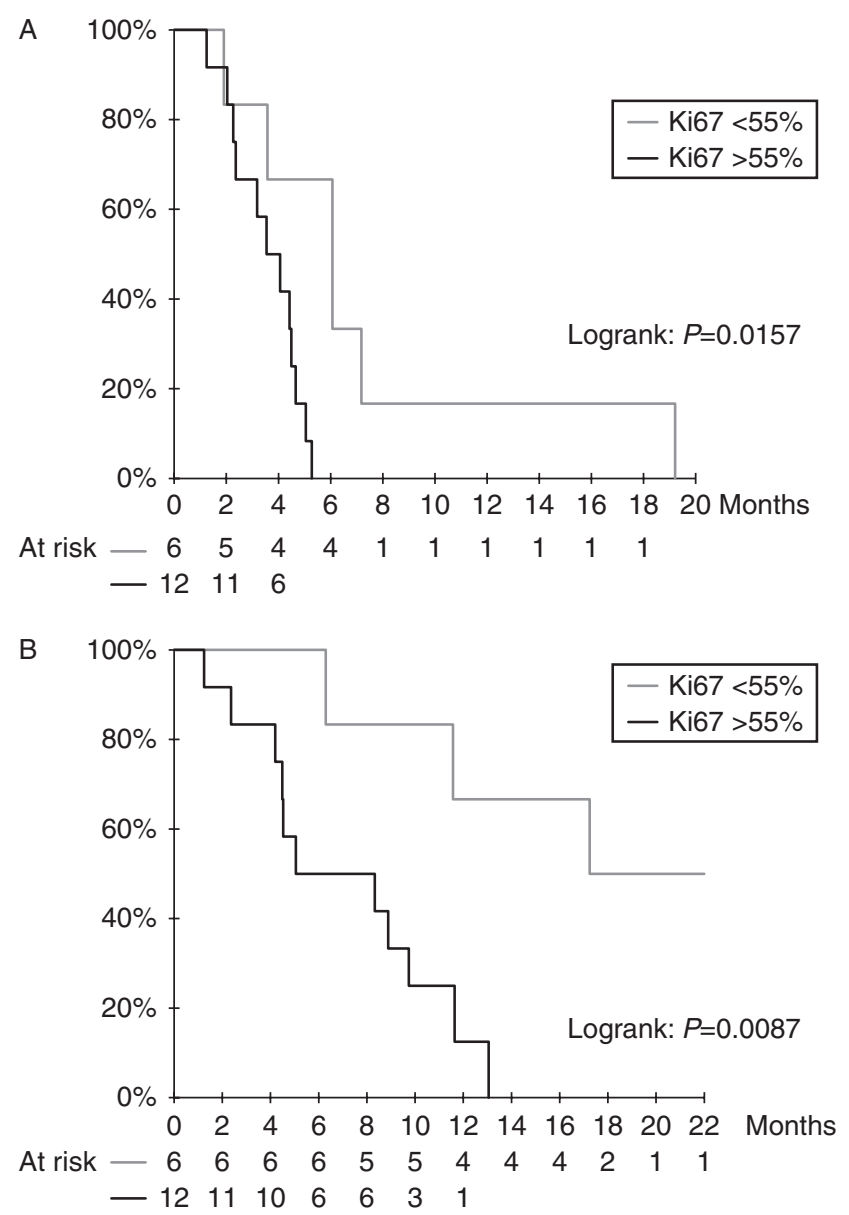

Figure 2

Survival in relation to Ki67 levels. (A) Progression-free survival curve. (B) Overall survival curve.

Published by Bioscientifica Ltd. 
Table 4 Safety

\begin{tabular}{|c|c|c|c|c|c|}
\hline \multirow[b]{2}{*}{ Toxicity observed } & \multicolumn{4}{|c|}{ Patients experiencing toxicity, $n(\%)$} & \multirow[b]{2}{*}{ Total $(\%)$} \\
\hline & Grade 1 & Grade 2 & Grade 3 & Grade 4 & \\
\hline \multicolumn{6}{|l|}{ Biological toxicity } \\
\hline Anemia & $7(35 \%)$ & $6(30 \%)$ & $2(10 \%)$ & 0 & $15(75 \%)$ \\
\hline Thrombopenia & $9(45 \%)$ & $3(15 \%)$ & $2(10 \%)$ & $2(10 \%)$ & $16(80 \%)$ \\
\hline Neutropenia & 0 & $4(20 \%)$ & $4(20 \%)$ & $3(15 \%)$ & $11(55 \%)$ \\
\hline $\begin{array}{c}\text { ASAT/ALAT } \\
\text { elevation }\end{array}$ & $3(15 \%)$ & $1(5 \%)$ & $2(10 \%)$ & 0 & $6(30 \%)$ \\
\hline Bilirubin elevation & 0 & $1(5 \%)$ & 0 & 0 & $1(5 \%)$ \\
\hline \multicolumn{6}{|l|}{ Clinical toxicity } \\
\hline Neurotoxicity & $11(55 \%)$ & $4(20 \%)$ & $1(5 \%)$ & 0 & $16(80 \%)$ \\
\hline Asthenia & $7(35 \%)$ & $8(40 \%)$ & $1(5 \%)$ & 0 & $16(80 \%)$ \\
\hline Nausea/vomiting & $1(5 \%)$ & $5(25 \%)$ & $2(10 \%)$ & 0 & $8(40 \%)$ \\
\hline Diarrhea & $3(15 \%)$ & $3(15 \%)$ & $1(5 \%)$ & 0 & $7(35 \%)$ \\
\hline Mucositis & $2(10 \%)$ & $1(5 \%)$ & 0 & 0 & $3(15 \%)$ \\
\hline $\begin{array}{l}\text { Hand foot skin } \\
\text { syndrome }\end{array}$ & $1(5 \%)$ & $1(5 \%)$ & 0 & 0 & $2(10 \%)$ \\
\hline
\end{tabular}

ASAT, aspartate amino-transferase; ALAT, alanine amino-transferase.

reported previously (Faggiano et al. 2007, Sorbye et al. 2012). Patients whose tumors were positive for CgA staining experienced a longer PFS and OS. A longer PFS and OS was also observed for patients with Ki67 below 55\% (Faggiano et al. 2007, Sorbye et al. 2012) in the univariate analysis. Interestingly, some patients who failed to respond to first-line platinum therapy responded or were stabilized under FOLFOX as reported previously for ovarian cancer (Pectasides et al. 2004, Sundar et al. 2004) and also in germ cell tumors (Theodore et al. 2008). However, whether this efficacy in cisplatin-resistant tumors is due to oxaliplatin alone or its combination with other agents such as 5-FU (FOLFOX) or gemcitabine (GEMOX) remains unknown (Stordal et al. 2007).

Table 5 Literature review of second-line studies in PDNEC

\begin{tabular}{|c|c|c|c|c|c|c|c|}
\hline References & $\begin{array}{c}\text { No. of } \\
\text { patients }\end{array}$ & Primary & $\begin{array}{l}\text { Modality of } \\
\text { diagnosis }\end{array}$ & Regimen & $\begin{array}{c}\text { PR rate } \\
(\%)\end{array}$ & $\begin{array}{l}\text { Median PFS } \\
\text { (months) }\end{array}$ & $\begin{array}{c}\text { Median OS } \\
\text { (months) }\end{array}$ \\
\hline Welin et al. (2011) & 25 & GEP, bronchial, UK & $\begin{array}{l}\text { Morphology or } \\
\text { Ki67 > } 20 \%\end{array}$ & $\begin{array}{c}\text { Temozolomide }+/- \\
\text { capecitabine }+/- \\
\text { bevacizumab }\end{array}$ & 33 & 6 & $22^{a}$ \\
\hline Olsen et al. (2012) & 28 & $\begin{array}{l}\text { GEP, bronchial, UK, } \\
\text { urologic }\end{array}$ & Ki67 > 20\% & Temozolomide & 0 & 2.4 & $3.5^{b}$ \\
\hline Hentic et al. (2012) & 19 & GEP & $\begin{array}{l}\text { Morphology } \\
\text { and Ki67 } \\
>20 \%\end{array}$ & FOLFIRI & 31 & 4 & $18^{a}$ \\
\hline Sorbye et al. (2012) & 100 & GEP & Ki67 > 20\% & $\begin{array}{l}\text { Temozolomide or } \\
\text { docetaxel or } \\
\text { others }\end{array}$ & 18 & 3 & $19^{a}$ \\
\hline Olsen et al. (2014) & 22 & GEP, UK & $\mathrm{Ki} 67>20 \%$ & Topotecan & 0 & 2.1 & $3.2^{\mathrm{b}}$ \\
\hline $\begin{array}{l}\text { Yamaguchi et al. } \\
\qquad(2014)\end{array}$ & 116 & GEP & $\begin{array}{l}\text { PDNEC, SCC, } \\
\text { MEEC, and } \\
\text { clinical NEC }\end{array}$ & $\begin{array}{l}\text { Amrubicin, Irinote- } \\
\text { can, S1, etoposi- } \\
\text { de + platinum, } \\
\text { or Irinotecan + } \\
\text { cisplatin }\end{array}$ & 11 & 2.1 & $6.3^{b}$ \\
\hline This study & 20 & $\begin{array}{l}\text { GEP, thoracic, UK, } \\
\text { urologic }\end{array}$ & $\begin{array}{l}\text { Morphology } \\
\text { and Ki67 } \\
>20 \%\end{array}$ & FOLFOX & 29 & 4.5 & $9.9^{b}$ \\
\hline
\end{tabular}

CR, complete response; PR, partial response; SD, stable disease; PFS, progression-free survival; OS, overall survival; GEP, gastroenteropancreatic; UK unknown; PDNEC, poorly differentiated neuroendocrine carcinoma; ABC, atypical bronchial carcinoid; SCC, small-cell carcinoma; MEEC, mixed-exocrine carcinoma with PDNEC component; FOLFIRI, folinic acid, 5-fluorouracil and irinotecan.

${ }^{\mathrm{a}}$ From diagnosis of metastatic disease.

${ }^{b}$ From second line.

http://erc.endocrinology-journals.org DOI: 10.1530/ERC-15-0075
(C) 2015 Society for Endocrinology Printed in Great Britain
Published by Bioscientifica Ltd 
As far as safety is concerned, adverse events were predominantly of grades $1-2$. One patient died of aspiration pneumonia during third cycle of FOLFOX due to bronchial fistula related to the esophagus primary; no evaluation was performed before this event and it was not possible to relate this death to tumor progression or response. No grade 4 event was observed, except for hematological toxicity. Grade 3 events occurred in 5\% of the patients except for vomiting. Neurotoxicity is an issue in this cisplatinpretreated population and should be carefully evaluated: $80 \%$ of the patients experienced all-grade neurotoxicity with $25 \%$ of grades $2-3$ and one patient had to stop oxaliplatin due to G3 toxicity, which was in accordance with what was observed in the colon cancer setting (de Gramont et al. 2000, Rothenberg et al. 2003, Goldberg et al. 2004, Sugihara et al. 2012). Finally, the full FOLFOX dose regimen as defined by an absence of dose adjustment during the study was given in eight out of 20 patients.

Our study has several limitations. First, the limited number of patients makes it difficult to perform extensive statistical analysis; in terms of level of evidence, this is a series of consecutive cases. Therefore, $P$ values need to be interpreted with caution. Prospective phase II and also national or international prospective cohorts constitute a way to achieve progress in this area, especially if combined with a pathological review of all registered cases. Secondly, a selection bias cannot be ruled out. Thirdly, the population of patients enrolled was heterogeneous in terms of cell subtypes, tumor primary location, and lines of previous therapy. Finally, this is a retrospective analysis, but we believe that such studies are key for very rare cancers to provide the first signal of antitumor activity.

To conclude, the FOLFOX regimen is feasible and seems to be active in poorly differentiated G3-NEC after cisplatinum-based chemotherapy. These findings warrant further confirmation in future larger prospective studies.

\section{Declaration of interest}

The authors declare that there is no conflict of interest that could be perceived as prejudicing the impartiality of the research reported.

\section{Funding}

This research did not receive any specific grant from any funding agency in the public, commercial or not-for-profit sector.

\section{Author contribution statement}

J Hadoux performed data analysis and wrote the manuscript. D Malka, D Planchard, J Guigay, V Boige, S Leboulleux, P Burtin, A Berdelou, Y Loriot,
C N Chougnet, D Déandréis, $M$ Schlumberger, and $M$ Ducreux were responsible for patient treatment and data analysis, and wrote the manuscript. J Y Scoazec and P Duvillard were responsible for expert pathological review and wrote the manuscript. C Caramella performed radiological review and wrote the manuscript. I Borget performed statistical analysis and wrote the manuscript. E Baudin directed this work and was responsible for patient treatment and data analysis and wrote the manuscript.

\section{Acknowledgements}

The authors thank Dr Adlen Foudi for English editing of the manuscript.

\section{References}

Asamura H, Kameya T, Matsuno Y, Noguchi M, Tada H, Ishikawa Y, Yokose T, Jiang S-X, Inoue T, Nakagawa K et al. 2006 Neuroendocrine neoplasms of the lung: a prognostic spectrum. Journal of Clinical Oncology $\mathbf{2 4}$ 70-76. (doi:10.1200/JCO.2005.04.1202)

Bajetta E, Catena L, Procopio G, De Dosso S, Bichisao E, Ferrari L, Martinetti A, Platania M, Verzoni E, Formisano B et al. 2007 Are capecitabine and oxaliplatin (XELOX) suitable treatments for progressing low-grade and high-grade neuroendocrine tumours? Cancer Chemotherapy and Pharmacology 59 637-642. (doi:10.1007/ s00280-006-0306-6)

Baudin E 2007 Gastroenteropancreatic endocrine tumors: clinical characterization before therapy. Nature Clinical Practice. Endocrinology \& Metabolism 3 228-239. (doi:10.1038/ncpendmet0425)

de Gramont A, Figer A, Seymour M, Homerin M, Hmissi A, Cassidy J, Boni C, Cortes-Funes H, Cervantes A, Freyer G et al. 2000 Leucovorin and fluorouracil with or without oxaliplatin as first-line treatment in advanced colorectal cancer. Journal of Clinical Oncology 18 2938-2947.

Du Z, Wang Y, Zhou Y, Wen F \& Li Q 2013 First-line irinotecan combined with 5-fluorouracil and leucovorin for high-grade metastatic gastrointestinal neuroendocrine carcinoma. Tumori 99 57-60. (doi:10.1700/1248.13789)

Eisenhauer EA, Therasse P, Bogaerts J, Schwartz LH, Sargent D, Ford R, Dancey J, Arbuck S, Gwyther S, Mooney M et al. 2009 New response evaluation criteria in solid tumours: revised RECIST guideline (version 1.1). European Journal of Cancer 45 228-247. (doi:10.1016/j.ejca.2008. 10.026)

Faggiano A, Sabourin J-C, Ducreux M, Lumbroso J, Duvillard P, Leboulleux S, Dromain C, Colao A, Schlumberger M \& Baudin E 2007 Pulmonary and extrapulmonary poorly differentiated large cell neuroendocrine carcinomas: diagnostic and prognostic features. Cancer 110 265-274. (doi:10.1002/cncr.22791)

Garrow GC, Greco FA \& Hainsworth JD 1993 Poorly differentiated neuroendocrine carcinoma of unknown primary tumor site. Seminars in Oncology 20 287-291.

Goldberg RM, Sargent DJ, Morton RF, Fuchs CS, Ramanathan RK, Williamson SK, Findlay BP, Pitot HC \& Alberts SR 2004 A randomized controlled trial of fluorouracil plus leucovorin, irinotecan, and oxaliplatin combinations in patients with previously untreated metastatic colorectal cancer. Journal of Clinical Oncology 22 23-30. (doi:10.1200/JCO.2004.09.046)

Hentic O, Hammel P, Couvelard A, Rebours V, Zappa M, Palazzo M, Maire F, Goujon G, Gillet A, Lévy P et al. 2012 FOLFIRI regimen: an effective second-line chemotherapy after failure of etoposideplatinum combination in patients with neuroendocrine carcinomas grade 3. Endocrine-Related Cancer 19 751-757. (doi:10.1530/ERC12-0002)

Published by Bioscientifica Ltd. 
Lim E, Yap YK, De Stavola BL, Nicholson AG \& Goldstraw P 2005 The impact of stage and cell type on the prognosis of pulmonary neuroendocrine tumors. Journal of Thoracic and Cardiovascular Surgery 130 969-972. (doi:10.1016/j.jtcvs.2005.05.041)

Madeira I, Terris B, Voss M, Denys A, Sauvanet A, Flejou JF, Vilgrain V, Belghiti J, Bernades P \& Ruszniewski P 1998 Prognostic factors in patients with endocrine tumours of the duodenopancreatic area. Gut 43 422-427. (doi:10.1136/gut.43.3.422)

Mascaux C, Paesmans M, Berghmans T, Branle F, Lafitte JJ, Lemaitre F, Meert AP, Vermylen P, Sculier JP \& European Lung Cancer Working Party (ELCWP) 2000 A systematic review of the role of etoposide and cisplatin in the chemotherapy of small cell lung cancer with methodology assessment and meta-analysis. Lung Cancer 30 23-36. (doi:10.1016/S0169-5002(00)00127-6)

Mitry E, Baudin E, Ducreux M, Sabourin JC, Rufié P, Aparicio T, Aparicio T, Lasser P, Elias D, Duvillard P et al. 1999 Treatment of poorly differentiated neuroendocrine tumours with etoposide and cisplatin. British Journal of Cancer 81 1351-1355. (doi:10.1038/sj.bjc. 6690325)

Moertel CG, Kvols LK, O'Connell MJ \& Rubin J 1991 Treatment of neuroendocrine carcinomas with combined etoposide and cisplatin. Evidence of major therapeutic activity in the anaplastic variants of these neoplasms. Cancer 68 227-232. (doi:10.1002/10970142(19910715)68:2<227::AID-CNCR2820680202>3.0.CO;2-I)

Okita NT, Kato K, Takahari D, Hirashima Y, Nakajima TE, Matsubara J, Hamaguchi T, Yamada Y, Shimada Y, Taniguchi H et al. 2011 Neuroendocrine tumors of the stomach: chemotherapy with cisplatin plus irinotecan is effective for gastric poorly-differentiated neuroendocrine carcinoma. Gastric Cancer 14 161-165. (doi:10.1007/ s10120-011-0025-5)

Olsen IH, Sørensen JB, Federspiel B, Kjaer A, Hansen CP, Knigge U \& Langer SW 2012 Temozolomide as second or third line treatment of patients with neuroendocrine carcinomas. Scientific World Journal 2012170496. (doi:10.1100/2012/170496)

Olsen IH, Knigge U, Federspiel B, Hansen CP, Skov A, Kjær A \& Langer SW 2014 Topotecan monotherapy in heavily pretreated patients with progressive advanced stage neuroendocrine carcinomas. Journal of Cancer 5 628-632. (doi:10.7150/jca.9409)

Panzuto F, Boninsegna L, Fazio N, Campana D, Pia Brizzi M, Capurso G, Scarpa A, De Braud F, Dogliotti L, Tomassetti P et al. 2011 Metastatic and locally advanced pancreatic endocrine carcinomas: analysis of factors associated with disease progression. Journal of Clinical Oncology 29 2372-2377. (doi:10.1200/JCO.2010.33.0688)

Pavel M, Baudin E, Couvelard A, Krenning E, Öberg K, Steinmüller T, Anlauf M, Wiedenmann B \& Salazar R 2012 ENETS Consensus Guidelines for the management of patients with liver and other distant metastases from neuroendocrine neoplasms of foregut, midgut, hindgut, and unknown primary. Neuroendocrinology 95 157-176. (doi:10.1159/000335597)

Pectasides D, Pectasides M, Farmakis D, Gaglia A, Koumarianou A, Nikolaou M, Koumpou M, Kountourakis P, Papaxoinis G, Mitrou P et al. 2004 Oxaliplatin plus high-dose leucovorin and 5-fluorouracil (FOLFOX 4) in platinum-resistant and taxane-pretreated ovarian cancer: a phase II study. Gynecologic Oncology 95 165-172. (doi:10.1016/ j.ygyno.2004.06.029)

Pujol JL, Carestia L \& Daurès JP 2000 Is there a case for cisplatin in the treatment of small-cell lung cancer? A meta-analysis of randomized trials of a cisplatin-containing regimen versus a regimen without this alkylating agent British Journal of Cancer 83 8-15. (doi:10.1054/bjoc. 2000.1164)

Rindi G 2010 The ENETS guidelines: the new TNM classification system. Tumori 96 806-809. (doi:10.1700/532.6380)

Rindi G, Azzoni C, La Rosa S, Klersy C, Paolotti D, Rappel S, Stolte M, Capella C, Bordi C \& Solcia E 1999 ECL cell tumor and poorly differentiated endocrine carcinoma of the stomach: prognostic evaluation by pathological analysis. Gastroenterology $116532-542$. (doi:10.1016/S0016-5085(99)70174-5)

Rothenberg ML, Oza AM, Bigelow RH, Berlin JD, Marshall JL, Ramanathan RK, Hart LL, Gupta S, Garay CA, Burger BG et al. 2003 Superiority of oxaliplatin and fluorouracil-leucovorin compared with either therapy alone in patients with progressive colorectal cancer after irinotecan and fluorouracil-leucovorin: interim results of a phase III trial. Journal of Clinical Oncology 21 2059-2069. (doi:10.1200/JCO.2003. $11.126)$

Scarpa A, Mantovani W, Capelli P, Beghelli S, Boninsegna L, Bettini R, Panzuto F, Pederzoli P, delle Fave G \& Falconi M 2010 Pancreatic endocrine tumors: improved TNM staging and histopathological grading permit a clinically efficient prognostic stratification of patients. Modern Pathology 23 824-833. (doi:10.1038/ modpathol.2010.58)

Sorbye H, Welin S, Langer SW, Vestermark LW, Holt N, Osterlund P, Dueland S, Hofsli E, Guren MG, Ohrling K et al. 2012 Predictive and prognostic factors for treatment and survival in 305 patients with advanced gastrointestinal neuroendocrine carcinoma (WHO G3): the NORDIC NEC study. Annals of Oncology 24 152-160. (doi:10.1093/ annonc/mds276)

Sorbye H, Strosberg J, Baudin E, Klimstra DS \& Yao JC 2014 Gastroenteropancreatic high-grade neuroendocrine carcinoma. Cancer 120 2814-2823. (doi:10.1002/cncr.28721)

Sørensen M, Pijls-Johannesma M \& Felip E 2010 Small-cell lung cancer: ESMO Clinical Practice Guidelines for diagnosis, treatment and follow-up. Annals of Oncology 21 v120-v125. (doi:10.1093/annonc/ mdt178)

Stordal B, Pavlakis N \& Davey R 2007 Oxaliplatin for the treatment of cisplatin-resistant cancer: a systematic review. Cancer Treatment Reviews 33 347-357. (doi:10.1016/j.ctrv.2007.01.009)

Strosberg JR, Cheema A, Weber J, Han G, Coppola D \& Kvols LK 2011 Prognostic validity of a novel American Joint Committee on Cancer Staging Classification for pancreatic neuroendocrine tumors. Journal of Clinical Oncology 29 3044-3049. (doi:10.1200/JCO.2011. 35.1817)

Sugihara K, Ohtsu A, Shimada Y, Mizunuma N, Gomi K, Lee P-H, Gramont A, Rothenberg ML, André T, Brienza S et al. 2012 Analysis of neurosensory adverse events induced by FOLFOX 4 treatment in colorectal cancer patients: a comparison between two Asian studies and four Western studies. Cancer Medicine 1 198-206. (doi:10.1002/ cam4.25)

Sundar S, Symonds RP, Decatris MP, Kumar DM, Osman A, Vasanthan S \& O'byrne KJ 2004 Phase II trial of oxaliplatin and 5-fluorouracil/ leucovorin combination in epithelial ovarian carcinoma relapsing within 2 years of platinum-based therapy. Gynecologic Oncology $\mathbf{9 4}$ 502-508. (doi:10.1016/j.ygyno.2004.04.020)

Theodore C, Chevreau C, Yataqhene Y, Fizazi K, Delord J-P, Lotz J-P, Geoffrois L, Kerbrat P, Bui V \& Flechon A 2008 A phase II multicenter study of oxaliplatin in combination with paclitaxel in poor prognosis patients who failed cisplatin-based chemotherapy for germcell tumors. Annals of Oncology 19 1465-1469. (doi:10.1093/annonc/ $\operatorname{mdn} 122)$

Travis WD, Linnoila RI, Tsokos MG, Hitchcock CL, Cutler GB, Nieman L, Chrousos G, Pass H \& Doppman J 1991 Neuroendocrine tumors of the lung with proposed criteria for large-cell neuroendocrine carcinoma. An ultrastructural, immunohistochemical, and flow cytometric study of 35 cases. American Journal of Surgical Pathology 15 529-553. (doi:10.1097/00000478-199106000-00003)

Travis WD, Rush W, Flieder DB, Falk R, Fleming MV, Gal AA \& Koss MN 1998 Survival analysis of 200 pulmonary neuroendocrine tumors with clarification of criteria for atypical carcinoid and its separation from typical carcinoid. American Journal of Surgical Pathology 22 934-944. (doi:10.1097/00000478-199808000-00003)

Travis WD, Brambilla E, Müller-Hermelink HK \& Harris CC 2004 World Health Organization Classification of Tumors. Pathology and Genetics of

Published by Bioscientifica Ltd. 
Tumors of the Lung, Pleura, Thymus and Heart. Lyon: International Agency for Research on Cancer (IARC) Press.

Vélayoudom-Céphise F-L, Duvillard P, Foucan L, Hadoux J, Chougnet CN, Leboulleux S, Malka D, Guigay J, Goere D, Debaere T et al. 2013 Are G3 ENETS neuroendocrine neoplasms heterogeneous? EndocrineRelated Cancer 20 649-657. (doi:10.1530/ERC-13-0027)

Welin S, Sorbye H, Sebjornsen S, Knappskog S, Busch C \& Oberg K 2011 Clinical effect of temozolomide-based chemotherapy in poorly differentiated endocrine carcinoma after progression on first-line chemotherapy. Cancer 117 4617-4622. (doi:10.1002/cncr. 26124)
Yao JC, Hassan M, Phan A, Dagohoy C, Leary C, Mares JE, Abdalla EK, Fleming JB, Vauthey J-N, Rashid A et al. 2008 One hundred years after "carcinoid": epidemiology of and prognostic factors for neuroendocrine tumors in 35,825 cases in the United States. Journal of Clinical Oncology 26 3063-3072. (doi:10.1200/JCO.2007. 15.4377)

Yamaguchi T, Machida N, Morizane C, Kasuga A, Takahashi H, Sudo K, Nishina T, Tobimatsu K, Ishido K, Furuse J et al. 2014 Multicenter retrospective analysis of systemic chemotherapy for advanced neuroendocrine carcinoma of the digestive system. Cancer Science $\mathbf{1 0 5}$ 1176-1181. (doi:10.1111/cas.12473)

Received in final form 13 February 2015

Accepted 11 March 2015

Made available online as an Accepted Preprint

13 March 2015
Published by Bioscientifica Ltd. 